\title{
Memoria, ficción y multilingüismo en "El boxea- dor polaco", un cuento de Eduardo Halfon
}

\author{
Memory, fiction and multilingualism in "El boxeador \\ polaco", a short story by Eduardo Halfon
}

\author{
An Van Hecke \\ ORCID: 0000-0001-7025-7758 \\ Katholieke Universiteit Leuven, Bélgica \\ an.vanhecke@kuleuven.be
}

Resumen:

Este artículo propone analizar el cuento "El boxeador polaco", que forma parte de la colección del mismo título (2008) de Eduardo Halfon. En varios de sus libros, que suelen ser una mezcla de lo ficticio y lo autobiográfico, Halfon desarrolla la problemática de la identidad judía. A veces hay un narrador que no se reconoce en ciertas tradiciones judías, pero que al mismo tiempo percibe lo judío como algo que lleva dentro, lo que se observa sobre todo en el respeto y la admiración por su abuelo. Este abuelo es precisamente uno de los dos protagonistas del cuento "El boxeador polaco". Los juegos sutiles entre las dos voces narrativas - del abuelo y del nieto-y entre los tres tiempos —el pasado lejano en Auschwitz, la infancia del narrador en Guatemala y el presente del narrador adulto- parecen ser estrategias literarias para enfrentarse a la conocida paradoja del trauma: la imposibilidad de hablar sobre un trauma, por un lado, y la fuerza de la lengua como herramienta para curar al traumatizado, por otro (Gilmore). ¿Cómo pasar a la literatura lo indecible del trauma? El abuelo rompe el silencio de sesenta años en los que no podía recordar aquel pasado doloroso. Cabe examinar en este contexto el carácter multilingüe del cuento, 
con referencias al yiddish, al alemán y al polaco. Es nuestro objetivo tratar de entender cómo Halfon maneja la difícil relación, no solo entre memoria y ficción, sino también entre lengua e identidad.

\section{Palabras clave:}

Guatemala, literatura del Holocausto, autoficción, trauma, multilingüismo.

\section{Abstract.}

This article proposes an analysis of the story "El boxeador polaco", which forms part of the short story collection with the same title (2008) by Eduardo Halfon. In several of his books, which are usually a mixture of fiction and autobiography, Halfon deals with the question of Jewish identity. Sometimes the narrator does not recognize himself in certain Jewish traditions, but at the same time, perceives Jewish identity as something that he carries inside, which can be inferred from the respect and admiration shown for his grandfather. This grandfather is one of the two protagonists of the story "El boxeador polaco". The subtle interplay between the two narrative voices - the grandfather's and the grandson's-and between the three periods - the distant past in Auschwitz, the narrator's childhood in Guatemala and the present of the adult narrator-, seems to be a literary strategy to confront the well-known paradox of trauma: the impossibility of speaking about a trauma, on the one hand, and the strength of language as a tool to heal the traumatized on the other (Gilmore). The grandfather breaks the silence of sixty years in which he could not talk about that painful past. In this context the multilingual nature of the story, with references to Yiddish, German and Polish, will be examined. We will try to understand how Halfon handles the difficult relationship, not only between memory and fiction, but also between language and identity.

Key words:

Guatemala, Holocaust literature, auto fiction, trauma, multilinguism. 
DOI: https://doi.org/10.36798/critlit.vi21.335

Recibido: 10 de febrero de 2020

Aceptado: 22 de julio de 2020

\section{Autoficción: la construcción de una identidad}

En el panorama de la literatura guatemalteca actual, Eduardo Halfon se ha convertido en una de las voces narrativas más llamativas. El ganador del Premio Nacional de Literatura Miguel Ángel Asturias 2018 se ha destacado por sus relatos cortos que se interconectan de tal forma que crean una sola obra que consiste en cuentos enlazados o "textos integrados" (Brescia y Romano). En este artículo se analiza el cuento "El boxeador polaco", que forma parte de la colección de cuentos homónima. La primera edición de El boxeador polaco, publicada en 2008, constaba de seis cuentos; su reedición en 2019 incluye también tres cuentos del libro La Pirueta (2010). ${ }^{1}$ Todos estos cuentos presentan un narrador en primera persona singular, llamado "Eduardo Halfon" por los otros personajes. En el prefacio a la nueva edición de 2019, con ocasión del décimo aniversario de la original, Halfon recuerda a "ese otro Eduardo Halfon, que en aquel entonces apenas nacía y que hoy aún me acompaña" (El boxeador 11). Este juego literario de confusión entre los nombres resulta ser un procedimiento apropiado dentro de la llamada autoficción, un género híbrido que se mueve entre lo ficticio y lo autobiográfico, y que se caracteriza por un "pacto ambiguo" en términos de Manuel Alberca (2007). También podemos definir los textos autobiográficos de Halfon, siguiendo a Angélica Tornero, como "yo-grafías" o "con-figuraciones de singularidades", que parten de una propuesta

${ }^{1}$ Se trata de los textos "Fantasma", "Postales" y "La Pirueta" (Halfon, El boxeador 103-186). 
de recepción en "una relación yo-otro, como encuentro dialógico", con narradores que relatan su vida desde un contexto histórico específico (Tornero 160-161). La separación entre el autor real y el yo-narrador ficticio, pero también la sutil relación entre ambos, se manifiesta ya desde el epígrafe que abre el libro, una cita de Henry Miller: "He pasado la máquina de escribir al otro cuarto, donde puedo verme en el espejo mientras escribo" (El boxeador 7). Además de la autorreflexión, el espejo también podría simbolizar aquí el desdoblamiento del escritor o la confesión camuflada de un yo íntimo que establece un juego complejo con un yo ficticio.

Matías Barchino, en su estudio de El boxeador polaco, considera que "el problema literario de la verdad y la ficción ... constituye la preocupación fundamental del escritor Eduardo Halfon en estos relatos” (9). En una entrevista en Casa de América en 2018, el mismo autor prefiere situar sus textos dentro de la ficción:

Creo que la clave ahí es que no son memorias. No escribo memorias, no es autobiografía, es ficción. ¿No? Todo lo que escribo es ficción. Y la ficción tiene la magia de convertir algo muy individual, una historia muy muy individual, muy particular, en algo universal. Y uso la palabra "magia" a propósito, porque no sabemos cómo sucede eso o por qué sucede eso. ("Eduardo Halfon...")

Sin embargo, el autor reconoce al mismo tiempo el carácter autobiográfico de estos textos: "Mi biografía es un telón de fondo. Yo pongo, digamos, la escenografía: . . . . Todos los elementos del escenario se corresponden con mi vida, pero el drama que sucede ante ellos, la historia que escribo ya no lo es" (cit. en Gordo). Halfon visualiza la relación entre ambos términos como sigue: "Todo es real, y todo es ficción. No son términos excluyentes. Realidad y ficción son dos círculos que se traslapan en un diagrama de Venn, y la literatura es lo que sucede en la intersección" (cit. en Ailouti).

Halfon nació en una familia de judíos, de origen polaco y libanés, en Guatemala, un país donde, como bien se sabe, se refugiaron mucho menos judíos que, por ejemplo, en México o Argentina. Por 
pertenecer a una minoría judía, Halfon ha demostrado un particular interés por otros grupos minoritarios situados al margen, como los indígenas en Guatemala o los gitanos en Europa. A primera vista, la historia de los judíos y su diáspora está muy alejada de la Guatemala profunda, tal como Halfon la describe en el primer cuento del libro, "Lejano". Sin embargo, como bien lo ha analizado Stephanie Pridgeon en su estudio de Mañana nunca lo hablamos, el autor "plantea la posibilidad de una identificación afectiva entre los judíos y los indígenas en el contexto del violento conflicto político" (Pridgeon 99). El narrador de El boxeador polaco a menudo expresa sus dudas sobre la identidad judía. En la novela Monasterio, el narrador cuenta que, al llegar a Tel Aviv, el taxista le preguntó si era judío: "Sonreí y le dije que a veces" (26). En ambos libros, el narrador no puede reconocerse en ciertas tradiciones judías, pero al mismo tiempo percibe lo judío como algo que lleva dentro, lo que se observa sobre todo en el respeto y la admiración por el abuelo.

Halfon cuestiona la identidad judía con escepticismo, autocrítica, humor e ironía cuando se pregunta, por ejemplo, si lo judío se lleva "en la sangre" (Monasterio 48). La autocrítica sigue siendo un ejercicio difícil ya que se trata de una historia muy rica, de más de 2000 años, pero que al mismo tiempo puede constituir una carga religiosa y cultural. Al igual que otros autores judíos, su identidad está marcada por el desarraigo, por el hecho de no tener lugar en este mundo: "No me siento guatemalteco y menos aún norteamericano. Soy un desarraigado, pero eso es muy judío también, esa diáspora permanente, el sentido de nomadismo" (cit. en Mendoza).

Con vistas al siguiente análisis, en el que se acudirá al concepto de posmemoria, cabe subrayar el papel de la autoficción tal como Mariela Peller lo ha analizado en su estudio sobre la obra del autor argentino Félix Bruzzone: "la autoficción es un procedimiento estético narrativo que está al servicio de la posmemoria porque permite elaborar, aunque de forma precaria y fallada, el duelo por las pérdidas acontecidas" (424). También Beatriz Velayos Amo subraya la estrecha relación entre autoficción y posmemoria en la obra de la autora chilena Lina Meruane. Aunque Halfon escribe desde un contexto muy diferente, comparte con estos autores la búsqueda 
desde un espacio autobiográfico marcado por un acontecimiento traumático: "La posmemoria se caracterizaría por una proyección de las memorias heredadas en una suerte de proceso creativo de recuperación, articulado por medio de la imaginación" (Forné cit. en Velayos Amo 179). ${ }^{2}$

\section{Memoria y ficción: el trauma del Holocausto}

La literatura sobre el Holocausto cuenta ya con innumerables textos en todos los idiomas. A menudo estos libros, que suelen situarse entre el testimonio y la ficción, han sido causa de controversias sobre los límites de la creación literaria. Antes de abordar el tema del Holocausto, muchos autores se han visto confrontados con las mismas preguntas: ¿Cómo escribir otro texto sobre un tema tan trabajado por otros? ¿Cómo hablar de los horrores del Holocausto que ni se pueden imaginar? ¿Qué perspectiva adoptar: la de la víctima o la del verdugo? También hay editores que, algo apenados, se han quejado de una "saturación del mercado" (Astro 112) y hasta la crítica literaria ha observado el gran reto de abordar el tema del Holocausto, como por ejemplo Fernández de Castro en su reseña del libro de Halfon: "Y en principio se diría imposible aportar una nueva historia de Auschwitz que no se (sic) la misma retahíla de espantos que llevamos contabilizados a costa de los campos de exterminio". El propio Halfon ha luchado con este dilema, tal como

${ }^{2}$ El concepto de posmemoria, desarrollado por Hirsch, en The Generation of Postmemory, para referirse a la conexión de los sucesores de los sobrevivientes del Holocausto con el pasado traumático de los padres o los abuelos, ha sido retomado en los estudios literarios de autores latinoamericanos, en particular en el contexto de las dictaduras en Argentina y Chile en la segunda mitad del siglo XX. Sin embargo, se ha señalado también la diferencia en el uso del concepto. Si en el caso de la literatura del Holocausto se trata de testimonios de los hijos o los nietos que no vivieron el trauma directamente, en la literatura posdictatorial argentina o chilena, los escritores, si son hijos de desaparecidos, son víctimas que han vivido personalmente la experiencia traumática (Velayos Amo 179). 
lo reconoce en una entrevista con Luis Figueroa en 2009, un año después de la publicación de El boxeador polaco:

No quería entrar al tema del Holocausto. No sabía cómo tratar un tema tan escabroso, tan cliché, de hecho ¿no?, de cuánta gente ha escrito sobre esto, otra historia más, otro nieto más, otro abuelo más, otro sobreviviente más. Entonces, estaba atrapado entre el miedo y el respeto. No sabía cómo manejarlo, hasta que finalmente le encuentro un derrotero, digamos, encuentro por dónde llevarla, y es la culminación de este libro. (“UFM.edu...”)

El objetivo de la presente investigación es tratar de revelar cómo Halfon maneja esta difícil relación entre memoria y ficción, y cómo logra distinguirse como una "voz fresca" (Fernández de Castro) dentro de la llamada literatura del Holocausto.

El cuento "El boxeador polaco" es un diálogo entre un nieto y su abuelo judío, quien le cuenta cómo logró sobrevivir los campos de concentración nazis, de Sachsenhausen y de Auschwitz. Se salvó gracias a un boxeador polaco en Auschwitz, quien la noche anterior a su juicio le había dicho en polaco "qué cosas sí decir durante ese juicio y qué cosas no decir durante ese juicio” (99). El abuelo perdió a toda su familia en la guerra. Los vio por última vez el día de su arresto, pero por una cuestión del azar fue salvado por las palabras del boxeador polaco, que también era judío. Se percibe un sutil juego entre las dos voces narrativas, la del abuelo y la del nieto, y entre tres tiempos: el pasado lejano en Auschwitz, la época de la infancia del narrador y el presente del narrador adulto en que se desarrolla también el diálogo. Parecen ser estrategias literarias para enfrentarse a la conocida paradoja del trauma que consiste en la imposibilidad de hablar sobre un trauma, por un lado, y la lengua como herramienta para curar al traumatizado, por otro (Gilmore y Kilby). El problema de la teoría del trauma, tal como lo analiza Kilby, es que no realza las maneras en las que el trauma ha sido experimentado en el momento mismo, sino más tarde como presencia inquietante. Esto lleva a las siguientes preguntas: ¿Cómo 
conocer el trauma? ¿Cómo explicar lo que no se puede explicar? (Kilby 217). Y también: ¿Cómo pasar a la literatura lo indecible del trauma del Holocausto? El cuento enfoca el momento en que el abuelo rompe el silencio de sesenta años, toda una vida en la que no podía ni quería recordar su pasado traumático. Veamos las primeras frases del cuento:

69752. Que era su número de teléfono. Que lo tenía tatuado allí, sobre su antebrazo izquierdo, para no olvidarlo. Eso me decía mi abuelo. Y eso creí mientras crecía. En los años setenta, los números telefónicos del país eran de cinco dígitos. (87)

Así lo creía el narrador de niño, pero rápidamente entendió "la broma telefónica". El abuelo de Halfon no es el único en haber recurrido a esta pequeña mentira del número telefónico. Otros judíos mayores cuentan en sus testimonios lo mismo (Guerrero). Los judíos que, por diversas razones del azar, sobrevivieron a los campos de concentración, tuvieron que buscar maneras de asumir una vida con el tatuaje. El autor Primo Levi encargó la grabación del número de Auschwitz en su tumba como si el número formara parte de su identidad. También en el caso del abuelo de Halfon, el número tatuado por un joven judío lo ha marcado profundamente: "Hipnotizado por aquellos cinco dígitos verdes y misteriosos que, mucho más que en el antebrazo, me parecía que él llevaba tatuados en alguna parte del alma" (Halfon, El boxeador 89). Cambiar la función del número, de marcador judío a número telefónico, es una estrategia de sobrevivencia, para poder olvidar el pasado y empezar una nueva vida en otro lugar. Surge entonces una tensión particular entre memoria y olvido, ya que, por un lado, el abuelo inventa el truco del número de teléfono "para no olvidarlo"; mientras que, por otro lado, toda su vida gira alrededor del esfuerzo por olvidar precisamente aquel pasado traumático. Durante tantos años el abuelo ha tratado de olvidarlo todo al no hablar del tema. El narrador realiza un trabajo de la memoria que puede poner incómodo al abuelo, pero que, en el fondo, solo está destinado a reflexionar sobre las experiencias de su propia familia. 
Gran parte de la historia se desarrolla desde la perspectiva de un niño. ${ }^{3}$ El narrador adulto evoca sus recuerdos de infancia, de cómo percibía a su abuelo. Son recuerdos llenos de amor y de ternura, de una nostalgia por una época feliz, como se observa en la estructura repetitiva de las siguientes frases. — todas empiezan por "me gustaba" - que se sigue repitiendo hasta seis veces en todo el fragmento:

Me gustaba su acento polaco. Me gustaba mojar el meñique (único rasgo físico que le heredé: ese par de meñiques cada día más combados) en su vasito de whisky. Me gustaba pedirle que me hiciera dibujos, aunque en realidad sólo sabía hacer un dibujo, trazado vertiginosamente, siempre idéntico, de un sinuoso y desfigurado sombrero. ... Pero sobre todo me gustaba aquel número. Su número. (87; énfasis mío)

Inicialmente, el niño no asocia el número con nada terrible, al contrario, le gusta, solo porque es de su abuelo, a quien adora. Al adoptar una perspectiva infantil, los temas difíciles de hablar se observan con cierta ingenuidad, desde la inocencia y hasta con sentido del humor. Las interpretaciones de un niño matizan la visión sobre contextos políticos y religiosos, al no entenderlos completamente. Según Perkowska, "el niño-protagonista registra estos hechos, pero no los interpreta" (607). Como en cualquier novela de aprendizaje o Bildungsroman, también en un cuento como este el niño evoluciona y va descubriendo el mundo, por más hostil que se presente.

Cabe distinguir aquí entre la memoria personal y colectiva. Partiendo del trabajo de Annette Kuhn, Perkowska subraya que "el trabajo de la memoria es un proceso muy personal, pero, al mismo tiempo, conecta los significados de memorias personales con una red más amplia de elementos culturales, económicos, sociales e históricos" (598). Halfon pertenece a la llamada tercera generación

${ }^{3} \mathrm{Al}$ igual que en otra obra de Halfon, Mañana nunca lo hablamos (2011), estudiada por Stephanie Pridgeon. 
del Holocausto, la de los nietos que quieren saber y recordar. La transmisión transgeneracional del trauma puede afectar no solo a la segunda, sino también a la tercera generación. No han vivido el trauma directamente, pero a menudo sufren las consecuencias o sienten una inquietud por conocer la verdad. El modelo de la posmemoria propuesto por Marianne Hirsch analiza estas experiencias de la segunda o tercera generación, de los que no han vivido los acontecimientos, sino que escucharon el relato de esas experiencias. Los hijos y nietos reinterpretan aquellas experiencias desde su presente (Hirsch, The Generation of Postmemory 35). Según Faúndez y Cornejo, "a nivel internacional, los estudios con tercera generación de familiares de víctimas del Holocausto son escasos, ya que la mayor parte de la investigación se ha centrado en la transmisión entre la primera y la segunda generación" (45). Sin embargo, recientemente nuevas narrativas de la tercera generación han visto la luz, como por ejemplo The Lost (2006) del autor estadounidense Daniel Mendelsohn, La Shoah de M. Durand (2015) de la autora belga Nathalie Skowronek y, en particular en América Latina, cabe mencionar Hija del silencio (1999) de la argentina Manuela Fingueret. En la contraportada de La Shoah de M. Durand leemos que, frente al silencio obligatorio de las dos generaciones anteriores, "la tercera generación ha intentado de una manera a veces torpe y excesiva desenterrar estos secretos poniendo la Shoah en el centro de todo" (traducción mía). Incluso está apareciendo ya una cuarta generación que quiere romper con estas actitudes, seguir adelante y ver hacia el futuro. Surgió entonces una situación algo paradójica: mientras que los abuelos se esforzaron en callarse para no implicar a sus hijos, para protegerlos incluso, los nietos se ponen a investigar aquel pasado con obsesión (Skowronek cit. en Astro 111). En el caso de Halfon, la Shoah es un tema fundamental, pero tampoco está en el centro de toda su narrativa, ya que desarrolla muchos otros temas. Sí se observa un deseo de revelar los secretos de la vida del abuelo, pero sin la intención de reivindicar algún derecho como nieto, ni de posicionarse como víctima. Además, es importante situar la obra de Halfon dentro del contexto específico de la literatura centroamericana. Perkowska sostiene que: 
la literatura y las artes visuales (el cine, la fotografía) centroamericanas emprenden un diálogo crítico ... . efectuando un trabajo de la memoria y del duelo postergado o (de)negado, y explorando diversas formas en que el trauma, la memoria y el duelo se expresan y materializan estéticamente. (599)

Tanto la voz del abuelo como la del niño se mueven entre dos tiempos. El abuelo recuerda un pasado lejano, de hace más de sesenta años, un pasado doloroso que observa desde un presente. El niño también se mueve entre dos tiempos: el de su infancia, en un pasado no muy lejano, y el mismo presente, en el que dialoga con el abuelo. El narrador Halfon, adulto, se mueve sutilmente entre estos tres tiempos. Una vez descubierta la verdad sobre el número, el niño empezaba a imaginarse historias sobre cómo llegó el tatuaje al antebrazo de su abuelo. Seleccionamos aquí la última de las tres historias imaginadas, que tiene un toque humorístico que alcanza lo surrealista:

O mi abuelo, de pie ante una taquilla de cine, insertando el brazo izquierdo a través de la redonda apertura en el vidrio por donde se pasan los billetes, y entonces, del otro lado de la ventanilla, una alemana gorda y peluda se ponía a ajustar los cinco dígitos en uno de esos selladores como de fecha variable que usan los bancos ... y luego, como si fuese una fecha importantísima, estampaba ella con ímpetu y para siempre el antebrazo de mi abuelo. (88)

Estimulado por el deseo de llenar los huecos de un silencio de muchas décadas, el niño demuestra una gran capacidad de imaginarse historias fabulosas, lo que de hecho continúa hasta el final del cuento, incluso después de haber escuchado la historia del boxeador polaco. Ante las muchas incógnitas, el narrador adulto también se deja llevar por la fuerza de la imaginación: "Intenté imaginarme el rostro del boxeador polaco, imaginarme sus puños, ... imaginarme sus palabras en polaco que lograron salvarle la vida a mi abuelo" (100-101). Los intentos de imaginarse aquel pasado lejano son muy parecidos a lo que hace el narrador de Lenta biografía de Sergio Chej- 
fec, autor judío argentino de la segunda generación. La novela autobiográfica de Chejfec consiste precisamente en una larga sucesión, no de recuerdos, sino de imaginaciones y suposiciones: “¿Cómo serán — habrán sido- mis tíos? . . Esas preguntas eran, ahora pienso, una manera sutil de imaginar: yo imaginaba cara, gestos, ojos ... Suponía las caras de mis tíos como variaciones de la suya" (Chejfec 12).

En El boxeador polaco parece que los últimos intentos de imaginarse los cabos sueltos de la historia del abuelo terminan en el fracaso, porque solo queda una imagen, una imagen terrible, que se sobrepone a todas las anteriores:

pero ya sólo logré imaginarme una cola eterna de individuos, todos desnudos, todos pálidos, todos enflaquecidos, todos llorando y rezando el Kaddish en absoluto silencio, todos piadosos de una religión cuya fe está basada en los números mientras esperan en cola para ser ellos mismos numerados. (101)

Al lado de la imaginación, aparece también el uso particular de la digresión. A primera vista parece una figura literaria común que tiene como principal objetivo hacer la lectura más amena y que consiste en una interrupción del hilo del discurso por medio de la introducción de un nuevo aspecto que puede desarrollarse en comparaciones, anécdotas o recuerdos (Estébanez Calderón 290). Sin embargo, por medio de asociaciones sorprendentes, estas digresiones crean nuevos hilos conductores a través del relato y se integran en la historia principal de una forma bien particular, hasta tal grado que el lector empieza a sospechar que es en la digresión donde puede estar la esencia del cuento. El narrador, de niño, le había preguntado a su mamá "cómo llegaban los bebés a las panzas de las mujeres" (96). Su mamá, algo avergonzada, le contó que "cuando una mujer quiere un bebé, va al doctor y éste le da una pastilla celeste si ella quiere un niñito o le da una pastilla rosada si ella quiere una niñita”. El niño entonces se imaginaba a sí mismo en un pequeño frasco de vidrio, esperando entre "un montón de niñitos" hasta que una señora llegara con el doctor y se lo tragara con un poquito de agua (97). 
Escribe entonces: "Jamás he logrado sacudirme la sensación de soledad y abandono que sentí metido en aquel frasco de vidrio.” De vez en cuando vuelve este recuerdo absurdo de su fantasía infantil y entonces enumera momentos de su vida en los que tuvo la misma sensación de soledad y de encierro. El último ejemplo de esta serie es: "la imagen claustrofóbica del calabozo oscuro y húmedo y apretado y harto de susurros donde estuvo encerrado mi abuelo, sesenta años atrás, en el Bloque Once, en Auschwitz” (98). Así, lo que parecía una anécdota inocente de la infancia, bajo la forma de una digresión narrativa, se conecta inesperadamente con la historia del abuelo: ambas historias se sobreponen por la sensación traumática de estar encerrado: Halfon, de niño, en un frasco imaginado; el abuelo, de joven, en un calabozo oscuro en Auschwitz. Resulta que estas digresiones, que suelen ser típicas del teatro, "en realidad, cumplen una función precisa de intensificación o complicación de la intriga y de provocación del interés de los espectadores" (Estébanez Calderón 290), que es exactamente lo que hace el narrador de Halfon.

En estos procesos, tanto de los recuerdos como de las imaginaciones, es importante señalar el papel que juegan las fotos. El abuelo "conservaba una foto familiar, una sola, ... que mantenía colgada junto a su cama" (91). Curiosamente, en su interpretación de la foto, el narrador confiesa que aquella foto le dejaba indiferente: "que a mí no me hacía sentir nada, como si aquellos pálidos rostros no fuesen de personas reales sino de personajes grises y anónimos arrancados de algún libro escolar de historia" (91-92). ${ }^{4}$ En cambio, otra foto, la del abuelo en bicicleta poco tiempo después de ser liberado del campo de concentración, sí afecta al narrador, quien la describe en el último cuento del libro: "joven, delgado, en saco y corbata, montado en una bicicleta en alguna calle desierta de Berlín" (El boxeador 189). Tan significativa es esta foto para Halfon que la usó

${ }^{4}$ La foto del abuelo joven con su familia fue publicada en el periódico Clarín, en un artículo de Halfon sobre su abuelo: “¿Habrá mi abuelo judío saboteado aviones nazis?". 
para la portada de la nueva edición de 2019. La foto del abuelo en la bicicleta refuerza nuevamente el carácter autobiográfico de la obra, de la misma manera en que lo hizo, por ejemplo, Margo Glantz en su autobiografía Las genealogías, al incluir fotos de su familia, lo que da más credibilidad a la historia contada sobre la migración judía. El abuelo de Halfon, de joven, mira directamente a la lente.

En los estudios de posmemoria, las fotografías familiares se convierten en un medio privilegiado puesto que poseen un fuerte poder simbólico y evocativo. En su artículo "Family Pictures: Maus, Mourning, and Post-Memory", Marianne Hirsch nota algo fundamental sobre las fotos de judíos sobrevivientes que circularon después del Holocausto, al observar la foto de una tía sentada en un entorno normal, en una casa: "No hay nada en la foto que indique su conexión con los eventos del Holocausto. . . L La foto solo dice: 'Estoy viva' o tal vez 'he sobrevivido', un mensaje tan simple, y al mismo tiempo tan cargado de significado que parece suplicar por una narración y un oyente, por una narración de sobrevivientes" (Hirsch, Family Pictures 5; traducción mía). De hecho, "los teóricos de la fotografía a menudo han señalado la presencia simultánea de muerte y vida en la foto" (Hirsch, Family Pictures 5). Este análisis de Hirsch explica bien la preferencia de Halfon por la foto del abuelo en la bicicleta, el único sobreviviente de la familia. La clara imagen de la cara del abuelo contrasta además con las caras olvidadas del cuento "El boxeador polaco". El abuelo dice no recordar el nombre ni la cara del lagerleiter, el director del campo. Tampoco conoció el nombre ni el rostro del boxeador polaco (100), sin duda por la oscuridad de la noche en que ambos compartieron la celda. Todas estas caras terminaron en el olvido.

En los estudios del trauma se ha investigado también la necesidad imperiosa de regresar al lugar de la violencia, la escena del crimen donde se sufrió el trauma (Kilby 222). Así, por ejemplo, Primo Levi regresó dos veces en su vida a Auschwitz: en 1965 y en 1982 (Belpoliti). En el caso del abuelo de Halfon, este regreso no es evidente. Cuando el narrador Halfon relata el momento de la muerte del abuelo, en el libro Monasterio (2014), cuenta que había expresado varias veces a su abuelo su deseo de ir a Lódź, la ciudad 
donde todo empezó. Con "el rostro entre cínico y desilusionado", el abuelo reaccionaba: "Para qué quiere usted ir a Polonia, me decía. No debe usted ir a Polonia, me decía. Los polacos, me decía, nos traicionaron" (Monasterio 108). Resulta algo sorprendente entonces que el abuelo le apunte después en un pequeño post-it la dirección de la casa en Łódź, lo que el nieto interpreta como una orden. No es el abuelo quien regresa, sino el nieto, pero animado por un deseo profundo del abuelo. ${ }^{5}$

La figura del abuelo aparece en todos los cuentos de esta colección (Barchino 10). Sea solo como una mención, sea en fragmentos largos, estas repeticiones con variantes lo convierten en un leitmotiv por excelencia. Al igual que otros hilos conductores, el tema del boxeador polaco que salvó la vida del abuelo crea conexiones intratextuales, que Matías Barchino en su análisis de Halfon ha llamado "hipertextuales" y que "configuran estructuras narrativas más grandes o hiperrelatos" (1). Barchino hace un recorrido de todas las evocaciones del abuelo polaco, en particular en los cuentos "Lejano", "Fumata blanca", "Twaineando" y "Epístrofe", pero también aparece en los cuentos del libro La Pirueta, integrados en la nueva edición de El boxeador polaco.

\section{Lengua e identidad}

El cuento "El boxeador polaco" también llama la atención por su multilingüismo. Hay referencias al yiddish, al alemán y al polaco. Del yiddish aparecen tres palabras, todas al inicio. Para empezar, el nombre "Oitze": "Yo le decía Oitze, porque él me decía Oitze" (87). El narrador añade que significa "alguna cursilería” en yiddish. Según la ficha biográfica del abuelo, incluida en el sitio web del Centro Mundial de Conmemoración de la Shoá, "Oitze" significa

${ }^{5}$ En 2018, Halfon publica Oh gueto mi amor, un libro ilustrado por David de las Heras. Vuelve la historia del abuelo, que es el inicio de una nueva historia, la del nieto que va a Lódź. 
"tesoro" en yiddish (León Tenenbaum). El apodo se usa igual de abuelo a nieto como de nieto a abuelo, una palabra poco frecuente que aparentemente se usa solo en su familia y refleja lo íntimo, lo personal. Luego surgen palabras en yiddish que refieren a la comida, lo que es típico de narraciones multilingües y, al igual que en las autobiografías de Glantz (1987) o Stavans (2001), estas palabras en yiddish suelen ser acompañadas de una traducción o explicación: el jrein, una tradicional salsa de rábano picante y remolachas, y el guefiltefish, el pescado (Halfon, El boxeador 87). El yiddish, que según Sergio Chejfec es un idioma "tan dulce y parecido a la masticación” (154), aparece aquí como el idioma de lo privado y de lo gastronómico. También hay palabras en alemán y tampoco sorprenden los campos semánticos de estas: el militarismo, los campos de concentración y el nazismo. Estas palabras aparecen casi todas con traducción, en la misma frase o en la siguiente: Rassenschande ('La vergüenza de la raza'), stubendienst ('el encargado de nuestro bloque'), juden eintreffen (sin traducción, significa "llegan judíos"), lagerleiter ('director'), Arbeit Macht Frei ('El trabajo libera') y, finalmente, Gnadenschuss ('un solo tiro en la nuca'). No hay frases en alemán, son solo palabras y expresiones, pero son suficientes para darle al texto un carácter multilingüe, cuya función consiste en reforzar la ilusión de realidad. Al mismo tiempo, el narrador adopta aquí el papel de traductor, un trabajo que realiza con mucho cuidado. La necesidad de la traducción se asocia al deseo de revelar los secretos callados del abuelo. Las palabras en yiddish y alemán en el texto son el reflejo de un multilingüismo literario y cultural más amplio, de un autor que se mueve entre diferentes culturas y lenguas.

A diferencia del yiddish y del alemán, lo que sí sorprende en el cuento es el papel del polaco, que es mucho más ambiguo. No hay palabras en esta lengua, aunque se le menciona constantemente. El abuelo "se negaba a hablar en polaco" y el narrador añade: "que él llevaba sesenta años negándose a decir una sola palabra en su lengua materna, en la lengua materna de aquellos que, en noviembre del treinta y nueve, decía él, lo habían traicionado" (100). Yasemin Yildiz, en su libro Beyond the Mother Tongue, plantea que el concepto de lengua materna supone un "romance" entre lengua e identidad, 
pero este no es el caso para todo el mundo, como bien lo ilustra el caso de Kafka: "The 'mother tongue' can be a site of alienation and disjuncture, as German was for Kafka” (Yildiz 203-204). A pesar de la firme negación por parte del abuelo, el polaco sigue muy presente y afecta mucho al narrador, quien le otorga incluso una connotación muy positiva: "Me gustaba su acento polaco" (87). Toda la narración del abuelo, en español, está marcada por el acento polaco. Paradójicamente, aunque el abuelo fue traicionado por los polacos, fue también gracias al polaco que se salvó. Casi al final del cuento, cuando el abuelo relata el encuentro con el boxeador, es muy llamativa la insistencia en que le hablaba toda la noche "en polaco", hasta siete veces, por lo que esta figura estilística de la repetición en Halfon sugiere sutilmente el gran impacto de la palabra "polaco", al igual que la frase "me gustaba" al inicio del cuento. El nieto le pregunta al abuelo qué le dijo el boxeador, pero no recibe respuesta:

Nunca supe si mi abuelo no recordaba las palabras del boxeador polaco, o si eligió no decírmelas, o si sencillamente ya no importaban, si habían cumplido ya su propósito como palabras y entonces habían desaparecido para siempre junto con el boxeador polaco que alguna noche oscura las pronunció. (100)

Ya no importa conocer el contenido de las palabras, porque la esencia de estas palabras polacas era que habían cumplido su función de salvación de vida. ${ }^{6}$

Primo Levi, en una entrevista, definió el polaco de los campos de concentración como "una lengua infernal", como "la lengua de la aniquilación", lo que se entiende en su caso ya que no lo entendía y lo escuchaba como extranjero. ${ }^{7}$ En cambio, para el abuelo de Hal-

${ }^{6}$ En su estudio sobre Primo Levi, David Gramling también ha señalado la importancia del multilingüismo en los campos de concentración para tener más probabilidad de sobrevivencia (180-181).

7 "El polaco era esa lengua incomprensible que nos había recibido al final del viaje, pero no era ni mucho menos el polaco de la población civil que escu- 
fon, puesto que el polaco era su lengua materna, el rechazo debió ser traumático. Llama la atención que el abuelo no es el único en haber rechazado esta lengua después de haber migrado a América Latina. También se observa en la abuela de Ilan Stavans, Bobbe Bela, sobre la que relata en su autobiografía On Borrowed Words. La abuela de Stavans huyó de Polonia en 1929 a la edad de veinte años. Hablaba con fluidez el polaco, el ruso y el yiddish. Desde su llegada a México, rechazó conscientemente hablar en polaco y en ruso (Stavans 52).

Frente al poder de las palabras, en todos los idiomas presentes en el texto, se observa también la fuerza del silencio. En el cuento aparece el silencio a tres niveles. Además del silencio del abuelo de casi sesenta años, están los silencios repentinos en la conversación con el nieto y en la última frase del cuento: el narrador se imagina a los judíos, antes de ser tatuados, "rezando el Kaddish en absoluto silencio" (101).

\section{Literatura y realidad}

En otro cuento titulado "Discurso en Póvoa", también de El boxeador polaco, el narrador vuelve sobre los cruces entre literatura y realidad, con motivo de una conferencia sobre el tema en la ciudad portuguesa de Póvoa. Para ilustrar la problemática, decide revelar el génesis del cuento "El boxeador polaco" y cuenta que hasta grabó la entrevista con su abuelo. Relata en detalle cómo logró llevar la realidad a la literatura a partir de una "simple historia del boxeador polaco" que le pareció "poderosamente literaria” (190). Grande fue

chamos hoy en los hoteles o en boca de nuestros acompañantes. Era un polaco zafio, vulgar, trufado de injurias e imprecaciones, y nosotros no comprendíamos aquello; era realmente una lengua infernal. El alemán lo era todavía más, desde luego; el alemán era la lengua de los opresores, de las matanzas, pero mucho de los nuestros - yo, entre otros - lo comprendíamos a retazos, no nos era desconocido, no era la lengua de la aniquilación. El polaco sí era la lengua de la aniquilación." (Primo Levi cit. en Belpoliti). 
su sorpresa al descubrir una mañana una entrevista en un periódico guatemalteco en la que su abuelo confirmaba "que se salvó de Auschwitz debido a - tuve que leerlo dos veces- sus habilidades como carpintero" (191). A primera vista, el narrador parece sentirse engañado y desilusionado, porque el cuento "El boxeador polaco", que pensábamos que había nacido de un proceso de pasar una anécdota real a la literatura "todo lindo y perfecto", como dice el mismo Halfon, resulta una gran mentira y se pregunta: “¿Qué pasó con el boxeador polaco, con Sherezade en disfraz?”. Pero entonces, el narrador concluye: "Y allí está. La literatura no es más que un buen truco, como el de un mago o un brujo ... que crea la ilusión de que la realidad es una" (191). La metáfora de Las mily una noches sugerida por el nombre de Sherezade, insinúa que la historia del Holocausto puede ser contada con variaciones infinitas (Astro 120), pero también puede referir la idea de la ejecución aplazada. Ilse Logie, en su análisis del cuento "El boxeador polaco", concluye de manera acertada:

O sea que no sólo el narrador, sino también el propio abuelo ha ido ficcionalizando su testimonio, lo ha puesto en escena, lo que muestra la imposibilidad de la reconstrucción documental en términos de "verdad factual". Esta información no va, sin embargo, en detrimento de la verdad de su historia, puesto que la disyuntiva ficción/no ficción aparece como accesoria. La finalidad consiste en la producción activa de realidad, en ir más allá de estos informes y documentos. De lo que se trata no es de ofrecer una representación fidedigna de los acontecimientos, sino de producirlos activamente en la potencia de la ficción para penetrar así más hondamente su realidad ... (Logie 227)

A menudo pensamos que la literatura ayuda a entender mejor la realidad y es lo que se observa inicialmente en el narrador de "El boxeador polaco", quien está obsesionado con entender la historia de su abuelo, con saber los detalles, con tener acceso a la verdad y, de ahí, poder convertirla en literatura. Sin embargo, como bien de- 
muestra el giro inesperado del cuento "Discurso en Póvoa", cuando esta realidad a su vez se vuelve incomprensible y confusa, tal vez cabe adoptar otra actitud hacia la literatura: la de una entrega total, dejarse llevar por los trucos del mago.

Podríamos concebir que Halfon no solo está traduciendo entre lenguas, sino que de alguna manera también realiza un trabajo de "traducción" entre géneros y registros de escritura, y hasta entre generaciones. En este cuento, memoria, autoficción y lengua están inextricablemente vinculadas. Entre los trucos de este mago, que también podríamos llamar estrategias literarias, vimos el juego ambiguo entre el yo ficticio y el real, así como el uso particular de la digresión y el multilingüismo, pero el análisis reveló también otra estrategia, a saber, el sentido del humor, como en la historia imaginada de la taquilla de cine (El boxeador 88). La cuestión judía, que se balancea entre continuidad y ruptura, es dura, pero se ve mitigada por el humor, que suele ser típico de los judíos. Halfon se enfrenta a la compleja cuestión de identidad, pero esto no le impide disfrutar también de las cosas placenteras de la vida, como de la relación amorosa con su pareja Lía que "dibujaba sus orgasmos" (El boxeador 75), del buen whisky que tomaba con el abuelo o de la música en un concierto de un pianista serbio entre las ruinas de Antigua, Guatemala. El lector termina por creerle todo a este mago que inventa una nueva literatura llena de trucos inesperados y que no deja de aspirar siempre a la verosimilitud.

\section{Bibliografía}

Ailouti, Marta. "Eduardo Halfon: 'Todo es real y todo es ficción". El Cultural, 3 agosto 2018, elcultural.com/Eduardo-Halfon-Todo-es-real-y-todo-es-ficcion.

Alberca, Manuel. El pacto ambiguo. De la novela autobiográfica a la autoficción. Biblioteca Nueva, 2007.

Astro, Alan. "Avatars of Third-Generation Holocaust Narrative in French and Spanish". Third-Generation Holocaust Narratives: Mem- 
ory in Memoir and Fiction, editado por Victoria Aarons, Lexington Books, 2016, pp. 103-130.

Barchino, Matías. "Los cuentos de Eduardo Halfon: hiperrelato y autoficción”. Lejana. Revista Crítica de Narrativa Breve, no. 6, 2013. pp. 1-13.

Belpoliti, Marco, transcriptor. "Regreso a Auschwitz". Entrevista a Primo Levi. Letras libres, no. 48, 30 septiembre 2005, www. letraslibres.com/espana-mexico/revista/regreso-auschwitz.

Brescia, Pablo y Evelia Romano, coordinadores. El ojo en el caleidoscopio. Universidad Nacional Autónoma de México, 2006.

Chejfec, Sergio. Lenta biografía. Alfaguara, 2007.

Estébanez Calderón, Demetrio. Diccionario de términos literarios. Alianza, 1999.

Faúndez, Ximena y Marcela Cornejo. "Aproximaciones al estudio de la Transmisión Transgeneracional del Trauma Psicosocial". Revista de Psicología, vol. 19, no. 2, agosto-diciembre 2010, pp. 31-54.

Fernández de Castro, Javier. "El boxeador polaco". ElBoomeran (g), 09 diciembre 2008, www.elboomeran.com/blog-post/189/5601/ javier-fernandez-de-castro/el-boxeador-polaco/.

Fingueret, Manuela. Hija del silencio. Planeta, 1999.

Gilmore, Leigh. The Limits of Autobiography: Trauma and Testimony. Cornell UP, 2001.

Glantz, Margo. Las genealogías. Lecturas mexicanas 82, Secretaría de Educación Pública (SEP), 1987.

Gordo, Alberto. "Eduardo Halfon: 'Si la literatura es mi casa, entonces yo estoy alquilado"'. El Cultural, 28 abril 2017, elcultural.com/Eduardo-Halfon-Si-la-literatura-es-mi-casa-entonces-yo-estoy-alquilado.

Gramling, David. "An Other Unspeakability: Levi and Lagers 2 pracha". New German Critique, vol. 39, no. 3, otoño 2012, pp. 165187. doi: https://doi.org/10.1215/0094033X-1677318.

Guerrero, José Antonio. "El número de teléfono de Lotte: la superviviente de Auschwitz". Ideal, 26 octubre 2018, www.ideal.es/ sociedad/numero-telefono-lotte-20181026082741-ntvo.html.

Halfon, Eduardo. El boxeador polaco. Libros del Asteroide, 2019. 
. “Habrá mi abuelo judío saboteado aviones nazis?”. Clarín, 10 diciembre 2016, www.clarin.com/sociedad/abuelo-judio-saboteado-aviones-nazis_0_H1Ga49E7l.html.

. La Pirueta. Pre-Textos, 2010.

- Mi obra es una novela en marcha. YouTube, publicado por Casa de América, 7 junio 2018, www.youtube.com/watch?v=0c4I1rMPV6w

. Monasterio. Libros del Asteroide, 2014.

. Oh gueto mi amor. Ilustrado por David de las Heras, Páginas de espuma, 2018.

Hirsch, Marianne. "Family pictures: Maus, Mourning and Post-Memory", Discourse: Journal for Theoretical Studies in Media and Culture, vol. 15, no. 2, invierno 1992-1993, pp. 3-29.

. The Generation of Postmemory. Writing and Visual Culture After the Holocaust. Columbia UP, 2012.

Kilby, Jane. "The writing of trauma: trauma theory and the liberty of reading". New Formations: a Journal of Culture, Theory \& Politics, no.47, 2002, pp. 217-230, usir.salford.ac.uk/1459/

"León Tenenbaum". Yad Vashem. Centro Mundial de Conmemoración de la Shoá, www.yadvashem.org/es/education/educational-materials/lesson-plans/educational-program/guatemala/tenenbaum.html

Logie, Ilse. "Un retorno a lo real? La tensión entre ficción y documento en la narrativa hispanoamericana actual", editado por Carlos Walker, Mil hojas: formas contemporáneas de la literatura, Hueders, 2017, pp. 201-231.

Mendelsohn, Daniel. The Lost: A Search for Six of Six Million. HarperCollins, 2006.

Mendoza, Ana. "Eduardo Halfon: 'La ansiedad de vivir es algo muy judío"”. Zenda, 27 junio 2018, www.zendalibros.com/eduardo-halfon-la-ansiedad-vivir-algo-judio/

Moreno Cabrera, Juan Carlos. Multilingüismo y lenguas en contacto. Síntesis, 2015.

Peller, Mariela. "(No) seguir buscando a mamá. Performance y posmemoria en Campo de mayo de Félix Bruzzone". Kamchatka. 
Revista de análisis cultural, no.11, julio 2018, pp. 419-440, doi: https://doi.org/10.7203/KAM.11.11221

Perkowska, Magdalena. "Infancia e historia: actos de la memoria en Dios tenía miedo de Vanessa Núñez Handal y Mañana nunca lo hablamos de Eduardo Halfon". Revista de Estudios Hispánicos, vol. 51, no. 3, 2017, pp. 595-620, doi: https://doi.org/10.1353/ rvs. 2017.0058

Pozuelo Yvancos, José María. De la autobiografía. Teoría y estilos. Crítica, 2006.

Pridgeon, Stephanie. "Silences between Jewishness and Indigeneity in Eduardo Halfon's Mañana nunca lo hablamos". Revista Canadiense de Estudios Hispánicos, vol. 42, no. 1, otoño 2017, pp. 99-121.

Skowronek, Nathalie. La Shoah de Monsieur Durand. Gallimard, 2015.

Stavans, Ilan. On borrowed words: A memoir of language. Penguin Books, 2001.

Tornero, Angélica, coordinadora. Yo-grafías: autoficción en la literatura y en el cine hispánicos. Síntesis, 2017.

UFM.edu - Libro El Boxeador Polaco por Eduardo Halfon: entrevista con Luis Figueroa. YouTube, publicado por Newmedia UFM, 28 febrero 2009, www.youtube.com/watch?v=AYfqh6CbmG4.

Velayos Amo, Beatriz. "Estancia en las fronteras del género: autoficción y posmemoria en Sangre en el ojo de Lina Meruane". Impossibilia. Revista internacional de estudios literarios, no. 14, 30 noviembre 2017, pp. 168-186.

Yildiz, Yasemin. Beyond the Mother Tongue. The Postmonolingual Condition. Fordham UP, 2012. 